\title{
The Process of Musical Interpretation and the Play-Element in Music
}

\author{
Ruslan Kashyrtsev
}

Lecturer of the Music Theory Department, postgraduate of $4^{\text {th }}$ year of study at Kharkiv I. P. Kotliarevsky National University of Arts, Ukraine

The research was conducted at the Department of Theory of Music of Kharkiv I. P. Kotliarevsky National University of Arts, Ukraine

\begin{abstract}
:
The article is devoted to examination of such phenomenon as musical interpretation, which incorporates various aspects of composer's and performer's creativity, listener's perception, different styles of musical art, creative communication in music. The attempt to find the traits of the play-element in the process of musical interpretation may help to define the mechanisms, through which "play" activity in music in general is realized. Systematic approaches of scholars of the play-element and theorists of artistic interpretation present great possibilities to conduct such a research.

Examination of theoretical points of view on beforementioned problems allowed to reach a conclusion that the play-element is inherent to the music and is expressed in the process of interpretation. This happens in the framework of the system "composer - performer - sound director - listener", in which artistic interpretation plays a significant role.
\end{abstract}

Keywords: music art, musical interpretation, artistic interpretation, play-element, J. Huizinga, "Homo Ludens", interpretology, musical communication.

\section{Introduction}

The problems of musical interpretation are relevant for modern musicology as they illuminate important aspects of thinking of both the composer and performer, their creativity, listener's perception of music, directions of development of music, its genres and forms. Usage of research on such problems as play-element of the culture (which inevitably transpires in different kinds of music-making and auditory perception) in the examination of the phenomenon of interpretation can open new perspectives to regard these problems in new ways. Illumination of play features in a communication system "composer - performer - sound director listener" might contain potential for research on theory of play-element of the culture and musical interpretation in discourse of musicology.

In this article, the attention is drawn to the questions of the play-element in music while using modern theory of musical interpretation, particularly, its performative kind. These aspects, as well as others, are examined in the works of several modern scholars. These works examine certain features of performer's rendition of composer's text, imagery-semantical and musically-expressive premises of performers' interpretation (E. Ansermet [2], I. Stravinsky [13], T. Adorno [1], N. Koryihalova [7], E. Gurenko [5], V. Moskalenko [9]); creation of new author's (co-author's in the case of secondary creativity) performative or compositional (in such genre as transcription) conception on the basis of original material, its individual stylistic dimensions (M. Borysenko [3]); reflective consciousness of the artist-interpreter (L. Shapovalova [11], [12]); understanding of musical communication as an interpretative phenomenon (Y. Nikolayevska [10]). Another domain, relevant for the topic of this article, is phenomenon of ludomusicality (R. Moseley [8]). Fundamental philosophical works on the play-element of the culture (J. Huizinga [6], R. Caillois [4]), supplemented by the sources on the stated above problems constitute research background of the article. 


\section{Problem discussion}

Application of the concept of "Homo Ludens", proposed in the work by J. Huizinga written in 1938, might be profitable for the research, aimed and the examination of the problems of musical interpretation, particularly, in the creative work of the composer and performer. The philosopher illuminates the presence of the playelement in the culture, which is reflected in the title of his book, "Homo Ludens: A Study of the Play-Element in Culture". J. Huizinga states: "culture plays in its initial phases" but at the same time "it never outgrows the play, it unfolds in play and as a play" [6: 242]. This viewpoint seems to be fair for musical art as well.

In the book "Man, Music and Play" by R. Caillois [4], it is possible to find a detailed analysis of this problem. The author suggests a typology of play in order to study this socio-cultural phenomenon, its influence on creativity, "depending upon whether $\langle\ldots\rangle$ the role of competition, chance, simulation, or vertigo is dominant" [4: 12]. R. Caillois recounts these categories in detail: 1) "competition" or "agôn" (from Greek, " $\alpha \gamma \omega v "$ - "a struggle") which "presupposes sustained attention, appropriate training, assiduous application, and the desire to win"; 2) "chance" or "alea" ("the Latin name for the game of dice") which "signifies and reveals the favor of destiny"; 3) "simulation" or "mimicry", expressed in "the temporary acceptance, if not of an illusion $\langle\ldots\rangle$, then at least of a closed, conventional, and, in certain respects, imaginary universe"; 4) "vertigo" or "ilinx", a category which is "based on the pursuit of vertigo and which consists of an attempt to momentarily destroy the stability of perception and inflict a kinds of voluptuous panic upon an otherwise lucid mind" [4: 15, 17, 19, 23]. In addition to these categories, R. Caillois distinguishes two main constituents of the play having dialectical relations: 1) "paidia" (from Greek " $\pi \alpha 1 \delta$ เó" - "children"), "a kind of uncontrolled fantasy" which is restricted with another component - 2) "ludus" (from Latin "a game") - "arbitrary, imperative, and purposely tedious conventions", which, in other words, are "the rules and limitations of the play" [4: 13]. Also, according to R. Caillois, "agôn" and "alea" as well "imply opposite and somewhat complementary attitudes" [4: 19].

The interconnection of the play and the music is the key point of research by R. Moseley "Keys to Play: Music as a Ludic Medium from Apollo to Nintendo", 2016. The scholar makes a fair statement that "music is not merely the outcome of a certain type of play" and "play, in turn, becomes the means by which such musical behavior is made audible" [8: 16]. This type of activity is defined by the researcher as "ludomusical", although he does not suggest the direct usage of this term to music in unambiguous way; instead, R. Moseley focuses his attention on the examination of musical games (including videogames), where the music might become an object of the play.

This article suggests another approach to the problem of play and music as attempts to discern the elements of the play within music art could lead to interesting conclusions. We must note in advance, that in this article we do not manifest that musical creativity is founded exclusively on the play component, as the great role in music belongs to assiduous work, which is usually regarded as an antinomy to play in the works by J. Huizinga [6] and R. Caillios [4]. J. Huizinga notes, that "music-making has all the formal features of the play", such as: 1) activity in a certain field; 2) repetitiveness (musical events occur regularly); 3 ) specific order, "procedure" of happening; 4) extraction of the listener from the "mundane world" [6: 76]. Another important argument is the presence of competitive, "agonal" component, existence of which in music and other arts is pointed out by J. Huizinga. Setting aside the presence of "agôn" category, we may discern in music another possible variants of play, proportions of which may be variable in different genres and styles. For instance, "alea" inevitably follows each and every performance, and in the styles suggesting improvisation this category becomes pivotal (one may reference such style of avant-garde music as aleatoric). "Mimicry" is also present as embodiment of performer's artistry; in the works and genres applying theatrical component (e.g. opera), "mimicry" acquires great importance; from the listener's side this category is expressed in a specific influence he experiences, which evokes his imagination ("paidia") and almost takes him into the realm of music by force. Even "ilinx" ("vertigo") is present in music to a certain degree, as while being captivated by the performance, a musician might lose "stability of perception", completely dissolving in the process of music-making and listening, which might be relevant in events merging music and dance, rock-concerts etc. Maintaining the balance "paidia - ludus" might be responsibility of a performer as well as of a listener (depending on the "rules" of the work, style, genre, type of a band or a public etc.). For instance, at a classical music concerts "conventions" typical for "ludus" will be much more rigorous than at a jam-session event, 
where "paidia", apparently, will be less restricted (we will disregard that "rules of play" in these two events will differ as well).

Be that as it may, problem of play and music should be considered in aspect of musical interpretation. Because if the play component has its place within music art, its examination on different levels of musical activity (composer - performer - sound director - listener) might be somewhat troublesome. Findings of modern interpretology, used in this research, might help in achieving the aim.

The word "interpretation" (from Latin "interpretari" - "explanation, description, comprehension") in the meaning of "musical or dramatic representation" is used in the research of renowned scholars of the past, such as T. Adorno [1], E. Ansermet [2] and I. Stravinsky [13]. In modern musicology "musical interpretation" or "artistic interpretation in music" is regarded both as a process and its specific result. The term "interpretation" might be applicable not only to the problems of performance (although it's the most natural "environment" for it), but also to another types of musical activity - of composer, performer, sound director, listener. Interpretology as a branch of musicology 'integrates variety of qualities and functions of performer's musical thinking" [12: 299] and has its aim in definition, substantiation, systematization and analysis of the ways in which the phenomenon of interpretation transpires.

"Problems of the artistic interpretation (the philosophical analysis)" by E. Gurenko [5] is an influential research on this topic. This book contains an attempt to systemize problems of research on musical interpretation; thus, this work allows to comprehend the "mechanism", through which interpretational process happens, that is founded on the following:

1. Interaction "author - performer" may acquire different forms depending on the type of art; for instance, in visual arts "the act of creation of artistic objects might be completely devoid of their recreation" [5: 22], that is a characteristic of "primary independent creativity" in static types of art. In musical art, dynamic by its nature, "primary relatively independent creativity" is present, which then must be reproduced in performance, "secondary relatively independent creativity". Thus, artistic interpretation is defined as "performer's treatment of product of primary [relatively independent - author's note] artistic activity" [5: 59].

2. A difference can be defined between these two terms: interpretation is a "reasonable variant of objectivation of a product of primary creative activity"; performance is a "set of specific operations (mainly, physical actions), carried out by interpreter and aimed at objectivation of performative idea" [5: 81].

3. Given that performative conception takes time to be created, E. Gurenko represents this process in "two sub-systems" [5: 85, 96]:

Sub-system 1, "a process of shaping the performer's idea", or "artistic projecting": a) "getting familiar with the product of primary [relatively independent - author's note] creative activity" (studying of the sheet music); b) "formation of performative conception".

Sub-system 2, "bringing the result of performative art to life as a material phenomenon" (performance): a) "in the process of rehearsals"; $b$ ) "in the act of public performance".

E. Gurenko suggests a definition of performer's creativity as well: "Secondary relatively independent creative activity, creative form of which transpires in a form of artistic interpretation" [5: 109]. In addition to that, the author gives a table, where the presence of interpretational components in different arts is presented in a schematic way [5: 104-105].

At the same time, this theory does not take the possibilities granted by computer sound-engineering into account. Nowadays musical creativity might be presented as well as "primary independent creativity" in such forms as "original mix", being exactly the same as it was crafted by the author or team of authors, performers, sound engineers and producers. From the listener's side of things, the recording is an integral, finished work, which is heard without any intermediaries (the only "intermediary" is a sound equipment, through which the recording is played). But theoretical positions by E. Gurenko remain relevant for the sphere of musical activity, with it supposing the studying of the sheet music and any kind of live-performance (including various improvisational activities).

This problem receives its partial solution in more recent works. V. Moskalenko [9] defines musical interpretation as "creative activity of musical thinking, organised by the intellect and aimed at reveal of expressive and content possibilities of a musical work" [9: 15] and proposes typology of artistic interpretation in music, including composer's interpretation. Another problem of interpretation is a correctness of interpretational version in the framework of the possibilities, foreshadowed in the work by its author and 
exceeding of which would be considered as a distortion of a composition causing loss of artistic integrity. It is this question that a research by V. Moskalenko is called to answer through suggesting various approaches to shaping of substantiated interpretation of the work. This problem has already become an object of examination in the past, when the process of interpretation was still not systemized (T. Adorno [1], E. Ansermet [2], I. Stravinsky [13]); Ukrainian musicologists pay attention to this problem as well, among them being L. Shapovalova [11, 12] and Y. Nikolayevska [10].

In the process of music-making distinguished by J. Huizinga traits of play activity can be observed: 1) certain space, in which interpretational process occurs and borders of which are defined by the content and fabula of the work; 2) repetitiveness of interpreter's actions when he practices the piece (rehearsal work), according to sub-systems, described by E. Gurenko (the whole process repeats with the work on new pieces, differing only in terms of time spent); 3) existence of certain order or forming of performative conception ("rules", according to respective "sub-systems"); 4) detachment of the interpreter from the real world, and on some occasions, from his usual musical and genre "environment".

Thus, musical interpretation contains the play-element in music. On the premise of examination of theoretical views, it is possible to reach the conclusions on this problem.

\section{Conclusion}

Thus, musical interpretation is marked by the same traits of the play, which have been described in R. Caillois' research. Constituents of the play, "paidia" ("fantasy") and "ludus" ("the rules of the play"), can be observed even on the level of interaction "work - interpreter": creative "impetus" of the performer is usually balanced by the "rules" of the work's text, as well as by another factors, ranging from individual capabilities of the performer himself to the type of concert event and the public present at it. Traits of each category used by R. Caillois to classify the play, are also present in musical interpretation. "Agôn" is also of crucial importance in musical art and in interpretation of works by other composers: 1) the performer enters some sort of "competition" with others (R. Moseley notes the elements of "competitive" play interaction between composers in certain musical genres [8]); 2) he strives to overcome the difficulties of the piece; 3) to some extent, the performer competes with the composer - if not personally, at least in artistic meaning ("creative discussion"), suggesting his own view on the imagery of the work; 4) musician opposes unwanted circumstances, which may impair the quality of the performance and spoil the concert event. The latter indicates that the presence of "alea": although, usually undesirable, it is still an inevitable factor as no performer is immune to mishaps as well as no performer can play the same piece twice exactly the same (as at least minimal difference will always be present). Describing play category of "mimicry", R. Caillois uses the word "interpretation" as its synonym [4: 21]. Definitely, this word is not used accidentally, because the performer, studying the composer's idea and enriching it with his own creative findings, has to demonstrate artistry in order to make it perceptible to the listener; on the other hand, the audience under the influence of the performer and the atmosphere of concert event can "enter" new dimension of musical images and find its "role" in it. "Paidia" (imagination) is used in this process directly, being bridled by another component of play, "ludus", represented by the "rules" of the concert event and by the work itself which "leads" the listener in accordance with the "scenario", suggested by the composer (and followed by the performer as well). The influence of "ilinx" ("vertigo", distorted perception) is the least obvious, although, incarnating the sonic image of the work, the performer might lose "touch with reality", falling in a trans-like state; the same might happen to the listener.

As it can be seen, the statements made above on the play-element within the process of musical interpretation correlate with the previous definitions on the play within musical art in general. Thus, we can make the following conclusion: the play component is inherent for music and finds its place within the process of musical interpretation.

\section{References}

[1] Adorno, T. (2008). Izbrannoe: sotsiologiya muzyiki [Selected: Sociology of Music]. Moscow, 448 [in Russian].

[2] Ansermet, E. (1976). Besedyi o muzyike [Talks about music]. Leningrad, 110 [in Russian]. 
[3] Borysenko, M. (2004). Zhanr transkryptsii v systemi indyvidualnoho kompozytorskoho styliu: dis. ...kandydata mystetstvoznavstva [Genre of the transcription in the system of composer's individual style]. (Candidate's thesis). Kharkiv I. P. Kotlyarevsky National University of Arts [in Ukrainian].

[4] Caillois, R. (2001). Man, Play, and Games. University of Illinois Press, 208 [in English].

[5] Gurenko, E. (1982). Problemyi hudozhestvennoy interpretatsii (filosofskiy analiz) [Problems of the artistic interpretation (the philosophical analysis)]. Novosibirsk, 256 [in Russian].

[6] Huizinga, J. (2011). Homo Ludens: A Study of the Play-Element in Culture. Saint-Petersburg, 416 [in Russian].

[7] Koryihalova, N. (1979). Interpretatsiya muzyki [Interpretation of music]. Leningrad, 208 [in Russian].

[8] Moseley, R. (2016). Keys to Play: Music as a Ludic Medium from Apollo to Nintendo. University of California Press, 452 [in English]. Open access on JSTOR: https://www.jstor.org/stable/10.1525/j.ctt1kc6k47

[9] Moskalenko, V. (2012). Lektsii po muzyikalnoy interpretatsii: uchebnoe posobie [Lectures on the musical interpretation: tutorial]. Kyiv, 272 [in Russian].

[10] Nikolayevska, Y. (2021). Musical communication as an interpretative phenomenon (based on the creative work of the 20th - early 21st centuries): Doctor in Art Studies thesis. Kharkiv I. P. Kotlyarevsky National University of Arts [in Ukrainian].

[11] Shapovalova, L. (2008). Muzyka yak analoh osobystosti: do problemy refleksyvnoi osobystosti [Music as an analogue of personality: to the problem of reflective persinality]. (Extended abstract of Doctor's thesis). National Music Academy of Ukraine named after P. I. Tchaikovsky. Kyiv, 34.

[12] Shapovalova, L. (2017). Interpretology as an integrative science. Problems of Interaction of Art, Pedagogy, Theory and Practice of Education, 46, 289-300 [in Russian].

[13] Stravinsky, I. (2012). Igor Stravinsky: hronika, poetika [Igor Stravinsky: Chronicle, Poetics]. Moscow - Saint-Petersburg, 368 [in Russian]. 